\title{
Representasi Mitologis Budaya dalam Novel Ronggeng Dukuh Paruk Karya Ahmad Tohari
}

\author{
Hadi Rumadi ${ }^{1}$ \\ ${ }^{1}$ Program Studi Pendidikan Bahasa dan Sastra Indonesia, Universitas Riau \\ Email: hadirumadipbsi@gmail.com
}

\begin{abstract}
This research is motivated as a part of human life which is implemented into the novel. The depiction of culture is not only seen in the natural life of humans, but more than that culture is not implanted through special literary learning. This is unique because fictitious literature can be a target of reflection of local cultural values. Cultural events become myths for the people who do it. This research problem formulation is a cultural mythological representation contained in the novel Ronggeng Dukuh Paruk by Ahmad Tohari? The purpose of this research is to describe the cultural mythological representation in the novel Ronggeng Dukuh Paruk by Ahmad Tohari. The method in this research is descriptive with the type of qualitative research. The results of the study are describing cultural mythological data that support twenty-six data representations of novel content related to the culture of ronggeng protest. This cultural element is illustrated through a story line that tells the characteristics of the novel characters. This cultural recognition cannot be avoided by the community as a mystical force of life.
\end{abstract}

Keywords : Representation, Mythological, Culture

\begin{abstract}
Abstrak.Penelitian ini dilatarbelakangi pentingnya unsur budaya sebagai bagian dari kehidupan manusia yang diimplementasikan ke dalam novel. Penggambaran budaya tak hanya terlihat dalam kehidupan alamiah manusia semata, namun lebih dari itu unsur budaya juga ditanamkan melalui pembelajaran sastra khususnya novel. Hal ini menjadi unik karena sastra yang bersifat fiktif dapat menjadi perantara pencerminan nilai budaya setempat. Peristiwa budaya menjadi mitos bagi masyarakat pelakunya yang bermanfaat dalam kebaikan hidup. Rumusan masalah penelitian ini yakni representasi mitologis budaya apasajakah yang terdapat dalam novel Ronggeng Dukuh Paruk karya Ahmad Tohari? Tujuan penelitian adalah mendeskripsikan representasi mitologis budaya dalam novel Ronggeng DukuhParuk karya Ahmad Tohari. Metode dalam penelitian ini adalah deskriptif dengan jenis penelitian kualitatif. Hasil penelitian yaitu memaparkan data mitologis budaya yang berjumlah dua puluh enam data representasi isi novel yang berkaitan dengan budaya pelaku ronggeng. Unsur budaya ini tergambar melalui serangkaian alur cerita yang mengisahkan karakteristik tokoh novel. Pengakuan budaya ini tak dapat dipisahkan oleh masayarakat pelakunya sebagai kekuatan mistis kehidupan.
\end{abstract}

Kata Kunci : Representasi, Mitologis, Budaya

\section{PENDAHULUAN}

Sastra merupakan ungkapan ekspresi manusia berdasarkan pengalaman, ide-ide, dan perasaan pengarang yang dituangkan dalam bentuk bahasa tulis dan lisan.Sehingga dikenal dengan sastra lisan dan sastra tulis. Keberadaan sastra lisan dan tulis ini dipengaruhi oleh perbedaan makna keduanya sesuai dengan fungsi dan implementasinya di lapangan. Berbicara mengenai sastra berarti berbicara tentang karya sastra.Karya sastra sesuai dengan genrenya terbagi atas prosa, puisi, dan drama. Untuk bagian prosa maka ada prosa lama dan prosa baru. Novel adalah prosa baru yang sarat 
dengan nilai kehidupan yang bermanfaat bagi manusia pembacanya. Manfaat ini sebagai pembentukan perwatakan seseorang yang berkaitan dengan sifat batin manusia yang memengaruhi atau hal-hal yang berhubungan dengan watak seorang tokoh.Sastra lisan di daerah Indonesia adalah bagian yang tidak terpisahkan dari khasanah nasional, karena kebudayaan daerah merupakan penunjang dalam perkembangan bahasa dan kebudayaan nasional. Berdasarkan pernyataan tersebut dapat dilihat bahwa kebudayaan daerah aspek sastra sangat berperan penting dalam perkembangan bahasa dan kebudayaan nasional.

Berbicara tentang kehidupan manusia berarti tidak lepas dari masalah sosial, budaya masyarakat dan sistem nilai yang tumbuh dan berkembang dalam kehidupan masyarakat.Tiap manusia senantiasa mempunyai suatu sistem nilai agar tiap tingkah laku anggota masyarakat tersebut.Pada dasarnya suatu sistem nilai adalah semacam jaringan yang terdiri sejumlah normanorma atau kaidah-kaidah maupun seperangkat kelaziman yang melengkapi suatu masyarakat.

Nilai merupakan sifat-sifat yang penting dan berguna bagi manusia karena selalu beorientasi pada kebenaran dan kesatuan dari norma-norma yang membentuk sistem nilai dan dalam kehidupan sehari-hari berwujud aturan yang harus dipatuhi setiap manusia yang hidup bermasyarakat. Jadi, tanpa adanya sistem nilai, masyarakat akan kehilangan arah dan tidak punya pandangan hidup yang teguh. Karya sastra memberikan manfaat yang luas terhadap pembacanya, yang indah dan menyenangkan dan bermanfaat.Salah satu manfaatnya karya sastra itu mengandung unsur nilai pendidikan, moral dan aspek budaya. Dari segi itulah merupakan wahana untuk meneruskan tradisi budaya bangsa dari generasi ke generasi sekarang dan akan datang.

Bergesernya makna nilai-nilai dalam kehidupan masyarakat antara lain terlihat pada perilaku kehidupan anggota-anggota masyarakat terutama diperkotaan. Masing-masing sibuk dengan urusannya sendiri, berpacu dalam waktu, berlomba dengan teman untuk mengejar karier dan masih banyak kesibukan yang lainnya.Toleransi dalam kehidupan diabaikan.Nilai-nilai selalu diinjak-injak demi mementingkan kepentingan sendiri.Salah satu penyebab bergeserkan nilai-nilai itu adalah dikarenakan masuk dan berkembangkan budaya asing yang dikenal dengan modernisasi melalui media cetak, dan media elektronik ditengah masyarakat.Hal ini tentu tidak akan bisa dibiarkan berkembang lama karena akan mengelamkan budaya sendiri, oleh karena itu sebagai generasi penerus sebaiknya mengangkat kembali budaya-budaya itu sehingga budaya itu tetap ada dan terpelihara.

Adapun rumusan masalah yang akan diulas oleh penulis adalah representasi mitologis budaya apasajakah yang terdapat dalam novel Ronggeng Dukuh Paruk karya Ahmad Tohari? Tujuan penelitian adalah mendeskripsikan nilai budaya dalam novel Ronggeng DukuhParuk karya Ahmad Tohari. Penelitian relevan pertama dalam penelitian ini adalah jurnal dalam artikel berjudulNilai Budaya Jawa dalam Novel Trilogi Ronggeng Karya Ahmad Tohari oleh Nurpaisah, Martono, dan Sesilia Sessi dari Universitas Tanjung Pura Pontianak. Hasil penelitiannya mengemukakan bahwa nilai budaya dalam novel Ronggeng Dukuh Paruk dapat dipahami dari latar cerita kebudayaan yang digunakan Ahmad Tohari untuk membangun kisah dalam novelnya. Itulah sebabnya diperlukan pemahamannya dalam menganalisis novel tersebut dengan memahami hal-hal yang terjadi dalam novel tersebut.

Penelitian relevan kedua berjudul Kajian Ronggeng Dukuh Paruk Ahmad Tohari dan SindenKarya Putwadmadi Admadipurwa Universitas Sebelas Maret 2013. Dimana dalam novelnya membahas tentang unsur-unsur pembangun sebuah novel yaitu, tema, alur, penokohan, setting, dan point of view.Dimana struktur merupakan totalitas dari beberapa unsur yang saling berkaitan dan merupakan satu kesatuan. Unsur-unsur tersebut saling berhubungan timbal balik, saling menentukan, saling mempengaruhi secara bersama membentuk suatu kesatuan yang utuh.

Penelitian relevan yang ketiga adalah artikel berjudul Representasi Ronggeng dalam Tiga Novel Indonesia yang ditulis oleh Yulianetta yang dipublikasikan di jurnal bahasa dan sastra volume 14 Nomor 1 bulan April 2014. Isi artikel mengungkapkan bahwa hasil kajian ketiga novel beragam, meskipun ada kesamaan. Tetapi pengarang menggambarkan bahwa ronggeng sebagai hasil artefak kebudayaan. 
Menurut Nurgiyantoro (2012:10), novel adalah sebuah karya prosa fiksi yang memiliki alur yang panjang menceritakan mengenai kehidupan pria dan wanita yang bersifat imajinatif. Seperti pada karya sastra yang lain, novel juga memiliki struktur yang terdiri dari tema, alur, tokoh dan penokohan (perwatakan), latar, sudut pandang, dan Semua aspek tersebut saling terkait, namun pada penelitian ini latar serta penokohan (perwatakan) lebih diutamakan.

Aminuddin (2002:67), mengemukakan bahwa latar dalam karya fiksi adalah gambaran tempat, waktu, maupun peristiwa, serta memiliki fungsi fisikal dan fungsi psikologis.Latar fisikal artinya latar menyebabkan cerita menjadi masuk akal atau logis, sedangkan latar psikologis artinya latar mampu menghadirkan makna tertentu sehingga dapat menyentuh emosi kejiwaan pembaca cerita.Tokoh adalah pelaku yang mengemban peristiwa dalam cerita, sehingga peristiwa tersebut dapat menjadi jalan cerita. Adapun penokohan (perwatakan) adalah cara pengarang menampilkan tokoh dalam cerita. Istilah tokoh menunjukkan pada orangnya, pelaku cerita, misalnya sebagai jawab terhadap pertanyaan: "Siapakah tokoh utama novel itu?", atau "Siapakah tokoh protagonis dan antagonis dalam novel itu?", dan sebagainya (Nurgiyantoro, 2012:165).Tokoh utama adalah tokoh yang diutamakan penceritanya dalam novel yang bersangkutan. la merupakan tokoh yang paling banyak diceritakan, baik sebagai pelaku kejadian maupun yang dikenai kejadian. Bahkan pada novel-novel tertentu, tokoh utama senantiasa hadir dalam setiap kejadian dan dapat ditemui dalam tiap halaman buku cerita yang bersangkutan.

Kebudayaan berasal dari bahasa Sansekerta Buddhayah, yakni bentuk jamak dari Buddhiyang berarti budi atau akal.Selain itu ada pula yang berpendapat bahwa istilah budaya merupakan tuturan kata majemuk "budi daya" yang berarti "daya dan budi". Sehingga dibedakan antara "budaya" yang berarti "daya dari budi" yang berupa cipta, karsa dan rasa, dengan "kebudayaan" yang berarti hasil dari cipta, karsa dan rasa (Koentjaraningrat, 2009:146). Menurut Abdurrahman (2011:27) bahwa kebudayaan meliputi segala perbuatan manusia seperti cara ia menghayati dan membuat upacara untuk kematian, kelahiran, seksualitas, makanan, sopan santun, pakaian, kesenian, ilmu pengetahuan dan agama

Menurut Poedjawijatna (1987:134) kebudayaan adalah semua tindakan dan hasil karya yang dilakukan oleh manusia untuk memberikan arti kepadaalam sekitarnya serta juga memberikan bentuk baru kepada alam. Dengan kata lain kebudayaan tidak lain dari usaha dan hasil manusia mengatasi alam dengan daya pikiran. Kebudayaan dapat diartikan sebagai hal-hal yang bersangkutan dengan akal. Sedangkan kata "budaya" merupakan majemuk dari "budi daya" yang berarti "daya dari budi".Jadi nilai-nilai kebudayaan adalah segala hal, yang merupakan hasil pemikiran, perilaku, serta pengalaman yang dijadikan sebagai pandangan tentang segala sesuatu.

Berkaitan dengan mitos, Junus (dalam Lubis, 2011:187), Pemanfaatan mitologi dalam karya sastra berkaitan erat dengan kehidupan manusia dan hubungan antarmanusia yang dikuasai mitosmitos. Sikap seseorang terhadap sesuatu menghasilkan mitos yang ada dalam dirinya.Persentuhan dan perkenalan dengan sesuatu menghasilkan mitos baru berdasarkan mitos yang ada.Mitos baru dapat berbeda dari sebelumnya dan tidak menutup kemungkinan menentang mitos yang ada.

Adapun menurut Fry, via Esten (dalam Lubis, 2011:187), persoalan mitos tidak mempermasalahkan kebenarannya, tetapi hanyalah membantu menerangkan dan mengarahkan gambaran yang jelas dalam hal kepercayaan masyarakat, tatanan hukum dan keadilan sejarah, struktur dan sistem sosial, lingkungan, serta kenyataan dunia kosmos. Mitos menjadi bagian kebudayaan masyarakat yang tak dapat dipisahkan sebagai bagian yang mandiri. Mitos dipegang teguh oleh pemercayanya sebagai suatu keyakinan yang hakiki yang bermanfaat bagi kehidupan.

\section{METODE PENELITIAN}

Jenis penelitian ini adalah kualitatif. Metode penelitian yang digunakan dalam penelitian ini adalah metode deskriptif.Dalam metode deskriptif data yang dikumpulkan adalah berupa kata-kata, kalima-kalimat, peristiwa-peristiwa, gambar, dan bukan berupa angka-angka.Penelitian kualitatif akan menghasilkan data deskripsi berupa kata-kata tertulis atau lisan dari orang-orang dan perilaku yang dapat diamati. Dengan demikian, laporan penelitian akan berupa kutipan-kutipan data untuk 
memberi gambaran penyajian laporan tersebut. Teknik pengumpulan data adalah dokumentasi dari novel. Sementara teknik analisis data adalah mengidentifikasi data, mendeskripsikan data, membahas hasil penelitian dan menyimpulkan hasil. Indikator Kinerjanya berarti bahwa setiap gerak laku tokoh maupun setiap situasi melatarbelakangi berbagai peristiwa akan dipaparkan dan dianalisis dengan menggunakan kata-kata atau kalimat yang menggambarkan mitologis budaya dalam novel. Sumber data dalam penelitian ini adalah teks tertulis berbentuk novel berjudul Ronggeng Dukuh Paruk karya Ahmad Tohari yang diterbitkan tahun 2011 di Jakarta, oleh penerbit PT Gramedia Pustaka Utama.

\section{HASIL DAN PEMBAHASAN}

Sesuai dengan metode penelitian yaitu deskriptif dengan memanfaatkan format dokumentasi, maka hasil penelitian ini dipaparkan dalam bentuk tabel dokumentasi data penelitian sesuai masalah penelitian. Tabel dokumentasi ini berisi paparan data dari dua puluh enam topik yang terdapat dalam novel Ronggeng Dukuh Paruk. Berikut hasil rekapitulasi penelitian.

\begin{tabular}{|c|c|c|c|}
\hline \multicolumn{4}{|c|}{$\begin{array}{l}\text { Tabel Rekapitulasi Hasil Penelitian } \\
\text { Representasi Mitologis Budaya Ronggeng Dukuh Paruk Karya Ahmad Tohari }\end{array}$} \\
\hline Nomor & Topik & Halaman & Data \\
\hline 1 & \multirow[t]{10}{*}{$\begin{array}{c}\text { Ronggeng } \\
\text { Dukuh Paruk }\end{array}$} & 10 & $\begin{array}{l}\text { Semua orang Dukuh Paruk tahu Ki Secamanggala, } \\
\text { moyang mereka jadi musuh kehidupan masyarakat. } \\
\text { Tetapi mereka memujannya. Kuburan Ki Secamangala } \\
\text { menjadi kiblat kehidupan bathin mereka. }\end{array}$ \\
\hline 2 & & 11 & $\begin{array}{l}\text { Srintil mendendangkan lagu kebangsaan para ronggeng } \\
\text { "senggot timbane, tiwas, ngegot ning ora sue". }\end{array}$ \\
\hline 3 & & 13 & $\begin{array}{l}\text { Seorang ronggeng sejati tidak bisa menjadi ronggeng } \\
\text { kecuali roh indang telah merasuk ke dalam tubuhnya. } \\
\text { Indang adalah semacam wangsit yang di muliakan di } \\
\text { dunia peronggengan. }\end{array}$ \\
\hline 4 & & 18 & $\begin{array}{l}\text { Saru hal yang di sembunyikan oleh Nyai Kartareja } \\
\text { terhadap siapapun itu, ketika dia meniupkan mantra } \\
\text { pekasih ke ubun-ubun Srintil. Mantra itu di percaya } \\
\text { akan membuat siapa saja terlihat lebih cantik. }\end{array}$ \\
\hline 5 & & 30 & $\begin{array}{l}\text { Laki-laki itu mencoba menghubungkan bathinnya } \\
\text { dengan ruh Ki Secamangala atau siapa saja yang } \\
\text { menguasai alam Dukuh Paruk sarana yang di ajarkan } \\
\text { adalah sebuah Tidung. }\end{array}$ \\
\hline 6 & & 36 & $\begin{array}{l}\text { Terutama pula kepada pemuda-pemuda yang } \\
\text { memasukkan uang ke dada Srintil bila ronggeng itu } \\
\text { menari Tole-Tole. }\end{array}$ \\
\hline 7 & & 40 & $\begin{array}{l}\text { Keris milik ayah tidak lebih dari } 2 \text { jengkal tangan ku, } \\
\text { sarungnya berlapis kuningan , tangkainya terbuat dari } \\
\text { kayu walikukum. }\end{array}$ \\
\hline 8 & & 44 & $\begin{array}{l}\text { Upacara pemandian seorang ronggeng adalah } \\
\text { peristiwa yang penting bagi orang di pedukuhan itu, } \\
\text { lagi pula amat jarang sekali }\end{array}$ \\
\hline 9 & & 51 & $\begin{array}{l}\text { Jauh-jauh hari kartareja sudah menentukan di mana } \\
\text { syarat terakhir yang harus di penuhi oleh Srintil } \\
\text { benama Malam Buka kelambu. }\end{array}$ \\
\hline 10 & & 54 & $\begin{array}{l}\text { Kartareja menentukan orang yang bisa melakukan } \\
\text { malam buka kelambu adalah orang yang bisa }\end{array}$ \\
\hline
\end{tabular}




\begin{tabular}{|c|c|c|c|}
\hline & & & memberikan sekeping uang emas. \\
\hline 11 & & 63 & $\begin{array}{l}\text { Lagu yang menjadi terkenal di Dukuh paruk semenjak } \\
\text { belasan anak kehilangan kedua orang tua aKibat racun } \\
\text { tempe bongkrek aKibat } 11 \text { tahun yang lalu. }\end{array}$ \\
\hline 12 & & 69 & $\begin{array}{l}\text { Kartareja menyalahkan pendupaan, sebuah gayung } \\
\text { dengan sebuah tangkainya yang tertanam di dalam } \\
\text { tanah. Celana kolor bekas,kutang bekas, serta pakaian } \\
\text { lainnya di lempar di atas genteng. }\end{array}$ \\
\hline 13 & & 86 & $\begin{array}{l}\text { Bagi orang dukuh paruk kehidupan tanpa calung dan } \\
\text { tembang ronggeng berasa hambar, calung dan rongeng } \\
\text { pula yang member kesempatan mereka bertayub dan } \\
\text { minum ciu sepuas puasnnya. }\end{array}$ \\
\hline 14 & & 89 & $\begin{array}{l}\text { Aku tahu benar perkawinan di Dukuh Paruk bukan } \\
\text { barang muluk, apalagi kudus, maka para perempuan } \\
\text { tak perlu memujannya. }\end{array}$ \\
\hline 15 & $\begin{array}{l}\text { Lintang } \\
\text { Kemukus Dini } \\
\text { Hari }\end{array}$ & 116 & $\begin{array}{l}\text { Telur ayam yang tertinggal dalam pertarangan karena } \\
\text { tidak bisa menetas itu diam-diam ditanam disalah satu } \\
\text { sudut kamar tidur Srintil. Lalu membacakan mantra } \\
\text { pemutus asmara. }\end{array}$ \\
\hline 16 & & 130 & $\begin{array}{l}\text { Seperti sore hari yang panas orang-orang duwuan } \\
\text { terpekur mendengarkan petikan kecapi Wirsiter. Ciplak } \\
\text { membawakan asmara Dahana. }\end{array}$ \\
\hline 17 & & 140 & $\begin{array}{l}\mathrm{Ki} \text { Secamenggala memberikan wasiatnya turun- } \\
\text { temurun agar ronggeng dan calung menjadi bagian } \\
\text { lestari pedukuhan kecil itu. }\end{array}$ \\
\hline 18 & & 144 & $\begin{array}{l}\text { Srintil suka menyanyikan lagu-lagu nina bobo untuk } \\
\text { menidurkan Goder. }\end{array}$ \\
\hline 19 & & 166 & $\begin{array}{l}\text { Selagi indang masih tinggal dalam diri Srintil maka ia } \\
\text { masih seorang ronggeng namun apabila indang } \\
\text { tersebut tidak ada pada seorang penari ronggeng, } \\
\text { maka ia tidak bisa di katakan sebagai ronggeng. }\end{array}$ \\
\hline 20 & & 179 & $\begin{array}{l}\text { Srintil seperti hendak menjadi temanten laik nya. Dia di } \\
\text { pingit, badannya di lulur dan saat hendak tidur ia di } \\
\text { suruh mengunyah } 1 \text { sampai } 2 \text { butir merica agar } \\
\text { suaranya tetap lantang dan jernih. }\end{array}$ \\
\hline 21 & & 193 & $\begin{array}{l}\text { Tangan kanan nya menggenggam sebuah botol kecil } \\
\text { sebesar kelinking. Apabila ibu jari nya menutup ke } \\
\text { lobang botol maka Srintil tidak dapat bernapas akibat } \\
\text { diberi jampi-jampi. }\end{array}$ \\
\hline 22 & & 201 & $\begin{array}{l}\text { Srintil diminta untuk menjadi seorang gowok di derah } \\
\text { alaswangkal. }\end{array}$ \\
\hline 23 & & 238 & $\begin{array}{l}\text { Jumat kliwon mendatang kita akan membersihkan } \\
\text { makam eyang Secamengala. Kita akan selamatan } \\
\text { marabahaya yang mungKin menimpa kehidupan harus } \\
\text { Kita tumbal. }\end{array}$ \\
\hline 24 & $\begin{array}{l}\text { Jantera } \\
\text { Bianglala }\end{array}$ & 254 & $\begin{array}{l}\text { Gerimis jatuh sebelum matahari terbenam, udara } \\
\text { lembab membawa bau tanah rumah yang terbakar } \\
\text { Dukuh Paruk meringkuk, kecil dan hina. Bagi Dukuh } \\
\text { Paruk itulah pertanda datangnya masa susah bagi } \\
\text { Kuala alit. }\end{array}$ \\
\hline
\end{tabular}




\begin{tabular}{|c|c|c|}
\hline 25 & 290 & $\begin{array}{l}\text { Ketika gadis-gadis lain sudah berkenalan dengan } \\
\text { buatan pabrik, perawan-perawan kecil dukuh Paruk } \\
\text { tetap akrab dengan ilo-ilo, gontho, puput. Dan suara } \\
\text { puput yang sampai ke telinganya bersama Kicau } \\
\text { branjangan dan ciplak. }\end{array}$ \\
\hline 26 & 300 & $\begin{array}{l}\text { Srintil menegakkan kepala, ia mendengar temabang } \\
\text { seorang amatiran yang menirukan Putut Manggung. }\end{array}$ \\
\hline
\end{tabular}

Berdasarkan data ujaran yang terdapat pada novel, terdapat nilai budaya yang menarik dicermati sebagai temuan hasil.Kecenderungan dari setiap kata memiliki nilai budaya yang menonjol dan berkaitan dengan setiap babnya. Dari data tersebut penulis mengangkat 10 data yang akan diulas secara deskriptif dengan peristiwa-peristiwa yang mendeskripsikan nilai budaya. Berikut ini adalah deskripsi data penilaian tentang 10 ujaran pilihan penelitian yang diambil dari 26 topik pada novel Ronggeng Dukuh Paruk.

\section{Ki Secamengela}

Ki Secamengela adalah seorang nenek moyang di Dukuh Paruk.Awalnya Ki Secamengela sengaja mencari daerah paling sunyi sebagai tempat menghabiskan riwayat keberandalannya. Di Dukuh Paruk inilah ia menitipkan darah dagingnya. Kuburan Ki Secamengela menjadi kiblat kehidupan kebathinan mereka. gumpalan abu kemenyan pada nisan kubur Ki secamengela membuktikan pola tingkah kebathinan orang Dukuh Paruk berpusat di sana.

\section{Roh Indang}

Indang adalah semacam wangsit yang di muliakan di dunia peronggengan bagi seseorang yang memiliki roh indang atau kemasukan roh indang ia akan di nobatkan menjadi seorang ronggeng. Srintil seorang anak kecil yang berusia 11 tahun kemasuan roh indang padahal sama sekali Srintil tidak pernah melihat, mengetahui, mengenal apalagi menari. Karena ia kemasukan roh indang ia dapat melakukan ronggeng dengan sanggat baik.

\section{Upacara pemandian Calon ronggeng}

Seorang calon ronggeng ketika ia ingin menjadi ronggeng sejati ia harus melakukan pemandian untuk calon ronggeng kemudian di bacakan mantra yang ditiupkan ke ubunubun. Kemudian tubuhnya di guyur air kembang gayung demi gayung.Setelah di mandikan rambut srintil di sanggul. Kemudian ronggeng itu dituntun ke depan pintu Cangkuk atau kuburan Ki Secamengela, dan kemudian ia menyembah dengan taqzim, lalu bangkit dan berjalan ke hadapan lingkaran para penabuh.

\section{Malam Bukak Kelambu}

Malam bukak kelambu ini adalah persyaratan kedua yang harus dipenuhi seorang calon ronggeng.Malam bukak kelambu adalah malam dimana seorang calon ronggeng menyerahkan keperawananya kepada setiap laki-laki yang mampu memenuhi persyaratan yang telah ditentukan.Dimana cerita dalam Ronggeng Dukuh Paruk ini persyaratannya adalah menyerahkan sekeping uang emas.Sayembara ini bisa diikuti oleh siapa saja mulai dari anak remaja, dewasa, dan bahkan yang sudah beristri.Bagi seorang istri yang suaminya bisa melakukan malam buka kelambu dengan seorang ronggeng dianggap sebagai suatu kehormatan dan memiliki kekuasaan.

\section{Mantra Pemutus Asmara}

Mantra pemutus asmara adalah susunan kata-kata yang menyalurkan sugesti dan kekuatan alam melalui jalur nonfisika dan bebas dari hukum-hukum tentang energi maupun mekanika yang biasa. Kekuatan itu tidak terelakkan kecuali oleh kekuatan lain yang segaris namun berlawanan arah. Dan mantra yang dipasang oleh Nyai Kartareja secara tak sengaja telah mendapatkan tandingannya. 


\section{Srintil Menjadi Sosok Gowok}

Dalam novel ini juga menceritakan tentang sosok gowok.Gowok adalah seorang perempuan yang disewa oleh seorang ayah bagi anak laki-lakinya yang sudah beranjak dewasa dan menjelang menikah. Seorang gowok akan memberikan pelajaran kepada anak laki-laki itu banyak hal perikehidupan berumah tangga. Dari keperluan dapur dan memperlakukan istri dengan baik.Selama menjadi gowok mereka harus tinggal bersama dan hanya berdua saja dan masa pergowokan biasanya berlangsung hanya beberapa hari.

7. Mantra Pekasih

Dalam novel ini juga menceritakan tentang Mantra Pekasih ini adalah mantra yang yang digunakan oleh Nyai Kartereja kepada Srintil saat ia akan melakukan tarian ronggeng. Dimana mantra pekasih ini dikenal mampu membuat orang yang telah dibacakan mantra ini akan terlihat lebih cantik dari yang sebenarnya. Mantra ini biasanya dibacakan kepada seseorang lalu ditiup di ubun-ubun seseorang tersebut.

\section{Mantra Menghubungkan Batin dan Ruh Ki Secamengela}

Orang-orang di Dukuh paruk saat merasakan kesedihan yang amat terdalam biasanya mendatangi atau mengunjungi pekuburan di Dukuh Paruk.Kemudian saat sampai di perkuburan tersebut seseorang tersebut mulai mencoba menghubungkan batinnya dengan ruh Ki Secamengela atau siapa saja yang menguasai alam Dukuh Paruk.Sarana yang diajarkan oleh nenek moyang mereka adalah sebuah Kidung yang dinyanyikan dengan segenap perasaannya.

\section{Ritual Penangkal Hujan}

Ritual penangkal hujan adalah salah satu ritual yang bisa digunakan oleh Dukuh Paruk. Dimana ritual ini dipercaya dapat menghentikan hujan atau menangkal agar tidak akan turunnya hujan. Ritual ini lakukan oleh Nyai Kartareja ketika selesai mendandani Srintil.Kartereja menyalakan pedupaan, yang diletakkan di sudut halaman.Sebuah gayung dengan tangkainya yang tertanam di dalam tanah.Celana kolor bekas, kutang bekas, serta pakaian dalam lainnya dilemparkan di atas genteng.Setelah itu Nyai kartareja berdiri ditengah halaman dengan wajah menatap langit.

\section{Kutut Manggung}

Kutut Manggung adalah penghayatan atas naluri keprimitifan berahi dalam tertib nilai tertentu sehingga terjadi beda antara berahi manusia dan berahi muyuk. Dia bertanggung jawab dan memiliki arah yang pasti, yakni garis penghubung antara manusia dan selera pemguasa alam.Kutut manggung juga bisa dikatakan sebagai peluKisan hasrat perhubungan ragawi antara laki-laki dengan perempuan dalam wawasan tertib kosmik; bahwa motivasi perhubungan ragawi itu adalah upaya mencapai tata-raharjaning bangsa manusia, yakni keseleraan hidupnnya.

Berdasarkan hasil penelitian yang telah dikemukakan, representasi mitologis budaya dalam novel ini mendeskripsikan bahwa banyak terdapat unsur mitos budaya pada novel Ronggeng Dukuh Paruk ini. Penyampaian cerita juga dapat dipahami dari jalan cerita dan dialog antar tokoh dan kebanyakan menceritakan tentang nilai budaya yang telah diceritakan dalam novel karya Ahmad Tohari ini.

Teori budaya sangat tepat diterapkan pada penelitian novel Ronggeng Dukuh Paruk.Dimana dalam novel ini berhubungan sangat erat dengan nilai budaya suatu masyarakat.Jika tidak ada yang mau mendalami nilai-nilai budaya bangsa kita sendiri, maka lunturlah nilai budaya yang telah diajarkan nenek moyang kita.Pesan yang ingin disampaikan pengaraang kepada pembaca adalah agar kita semua mau dan mampu melihat seseorang itu tidak hanya dari luarnya saja melainkan juga dari hatinya.Dan agar Kita mau berpikir mengenai tragedi-tragedi kemanusiaan yang terjadi di sekeliling kita. Jangan gampang terpengaruh dengan keadaan duniawi karena suatu saat penyesalan akan datang dalam hidupmu. 


\section{KESIMPULAN}

Berdasarkan hasil penelitian yang telah dikemukakan dari novel berjudul Ronggeng Dukuh Paruk karya Ahmad Tohari sangat berkaitan erat dengan nilai-nilai budaya karena di dalam novel ini ceritannya berkaitan dengan kepercayaan-kepercayaan dengan adanya ronggeng di pedukuhan tersebut. Tokoh-tokoh di dalam novel tersebut sangat menjunjung tinggi nilai-nilai budaya yang telah diajarkan oleh nenek moyang mereka terdahulu. dari awal novel ini banyak terdapat nilai-nilai budaya yang telah di ajarkan oleh nenek moyang mereka tentang kepercayaan bahwa menjadi ronggeng itu adalah suatu hal yang penting dan untuk menjadi seorang ronggeng haruslah memiliki syarat seperti upacara pemandian yang secara turun temurun di lakukan di depan cungkuk making Ki Secamengela dan malam buka kelambu. Selain itu, banyak terdapat mantra-mantra seperti mantra pekasih dan pemutus kasih sebagai bagian representasi unsur budaya aspek sastra lisan.

\section{DAFTAR PUSTAKA}

Abdurrahman. 2011. Nilai-nilai Budaya dalam Kaba Minangkabau. Padang: UNP Press.

Aminuddin. 2002. Pengantar Apresiasi Puisi. Bandung: Sinar Baru Algensindo.

Aminuddin. 2009. Pengantar Apresiasi Karya Sastra. Bandung. Sinar Baru Algesindo.

Anwar, Ahyar. 2015. Teori Sosial Sastra. Yogyakarta: Ombak.

Endraswara, Suwardi. 2013. Sosiologi Sastra. Yogyakarta: Ombak.

Ismawati, Esti. 2005. Pengajaran Sastra. Yogayakarta: Ombak.

Koenjaraningrat.2009. Manusia dan Kebudayaan.Jakarta: Djambatan.

Lubis, Bustanuddin. 2011. Mitologi Nusantara:Penerapan Teori Mitologi Nusantara. Bengkulu :Quiksi.

Nurgiyantoro, Burhan.2012. Teori Perkajian Fiksi. Yogyakarta: Gadjah Mada University Press.

Nurpiasah, Martono, dan Sesilia Selli. 2014. Nilai Budaya Jawa dalam Novel Trilogi Ronggeng Dukuh Paruk Karya Ahmad Tohari. Jurnal Pendidikan dan Pembelajaran Khatulistiwa, Vol 3 No 2.

Poedjawijatna, I.R.1987. Manusia dan Alamnya. Jakarta: Bina Aksara.

Rumadi, Hadi dan Syafrial. 2017.Apresiasi Prosa Fiksi. Pekanbaru: Alaf Riau.

Sehandi, Yohanes. 2016. Mengenal 25 Teori Sastra. Yogyakarta: Ombak.

Waluyo, Herman J. 2017. Pengkajian dan Apresiasi Prosa Fiksi. Yogyakarta: Ombak.

Yulianetta. 2014. Representasi Ronggeng dalam Tiga Novel Indonesia. Jurnal Bahasa dan Sastra Vol

14 No 1 tahun 2014. 